\title{
Infantile handling, activity deprivation, and subsequent wheel running behavior'
}

\author{
RODERICK WONG, H. WILLARD BRADLEY AND JOHN L. JAMIESON
}

UNIVERSITY OF BRITISH COLUMBIA

Male rats within a litter were randomly assigned to either a handled or nonhandled condition during the second day after their birth. The $S s$ in the handled group were given tactile stimulation on Days 3-21, and the control group was left undisturbed during that period. On Day 22 Ss were housed in individual cages and were kept there until they were 60 days old. On Day 62 Ss were placed under one of four activity deprivation conditions: $0,5,22 \frac{1}{2}$, and $46 \frac{1}{2} \mathrm{hr}$. Each $S$ was tested in an activity wheel under all four conditions with four different orders of conditions being followed. Although the nonhandled $S$ s were consistently more active than the handled $S s$ under all the deprivation conditions, this difference was not statistically significant. Multiple comparisons among the deprivation conditions indicated that Ss exhibited greater wheel running after $46 \frac{1}{2} \mathrm{hr}$. of confinement than they did after lower degrees of deprivation.

Although the evidence supporting the notion of an "activity drive effect" occurring when animals are tested on activity wheels after short periods of activity deprivation is substantial (Hill, 1956; Marks, Narver, \& Bridges, 1966; and Shirley, 1928), little has been done to analyze the mechanisms underlying this phenomenon. In the discussion of his results Hill views physical restriction as a motivational antecedent for the operational definition of "activity as an autonomous drive." It may be argued that restricting an animal's activity by confining it in a small cage has other consequences. Such treatment may be stress-inducing.

A procedure which is commonly used to induce stress is to immobilize the animal in a small wire mesh cone. Data by Ader (1964) has indicated that one of the consequences of subjecting rats to physical immobility (just as they approach their daily period of peak activity) is the appearance of gastric erosions. The appearance of such erosions in an animal is generally regarded as a response to stress. If the phenomenon of the "activity drive effect" is due in part to heightened emotionality resulting from the stress of physical restriction, it is possible to assess the magnitude of this effect. This could be achieved by subjecting animals to infantile handling.

The literature on the behavioral and physiological effects of supernormal stimulation of infant rats is considerable (Levine, 1962). Compared with litter mates who have not received such infantile stimulation, adult rats which have been handled during infancy are larger and more resistant to stress. It follows that animals given such early stimulation would be less likely to be affected by the stress-induced effects of physical restriction. A comparison between handled and nonhandled Ss would provide a means of assessing the status of "activity as an autonomous drive."

It is hypothesized that subsequent hyperactivity following activity restriction is mediated by some motive arising from emotional reactivity. As a consequence of this confinement operation, the animal is in a heightened drive state and the subsequent wheel running serves to reduce the aversiveness of this state. If the usual increase in activity which an animal exhibits after activity restriction is mediated by such a motive, it is expected that handled animals would not be as affected by the response deprivation operation as would nonhandled animals. Because of their reduced emotionality resulting from their early experience, the handled animals would not be as likely to exhibit the "activity drive effect" as would the nonhandled control animals.

Method

Twenty-four male albino rats from the Wistar strain from four litters were used as Ss. They were randomly assigned from their litters after birth to either the handled or the control condition, and were housed by litters until they were weaned at 21 days. The procedure used in the handling treatment was described in Wong (1966). On Day 22 the handled male $\mathrm{Ss}$ in a given litter were weaned and housed in individual 8 in. $x 4$ in. $x 4$ in. wire mesh cages. Their nonhandled counterparts in the litter were assigned to similar housing conditions. All Ss were housed in the small cages on an ad lib diet until they were 60 days old. At this age the size of the Ss was such that they were not able to stand and lie at full length in the cage, but they were able to make bodily movements in circling.

On Day 61 all Ss were moved from their individual cages into larger 10 in. $\times 12$ in. $\times 7-1 / 2$ in. cages. They were housed four to a cage according to their previous handling treatment. After $24 \mathrm{hr}$. in the group cage each $\mathrm{S}$ was placed under one of the four activity deprivation conditions: 0 (control), 5, 22-1/2, and $46-1 / 2$ $\mathbf{h r}$. In the experiment each $\mathrm{S}$ was tested under all four conditions of confinement, four different orders of conditions being used. Each $S$ was tested four times under each condition with the same order of conditions being used each time.

A given S was tested once every other day, so that eight days were required to complete the four experimental conditions. For a given day the Ss that were to be tested under the $5,22-1 / 2$ and $46-1 / 2 \mathrm{hr}$. conditions were moved from their respective group cages to a small cage at the appropriate number of hours 


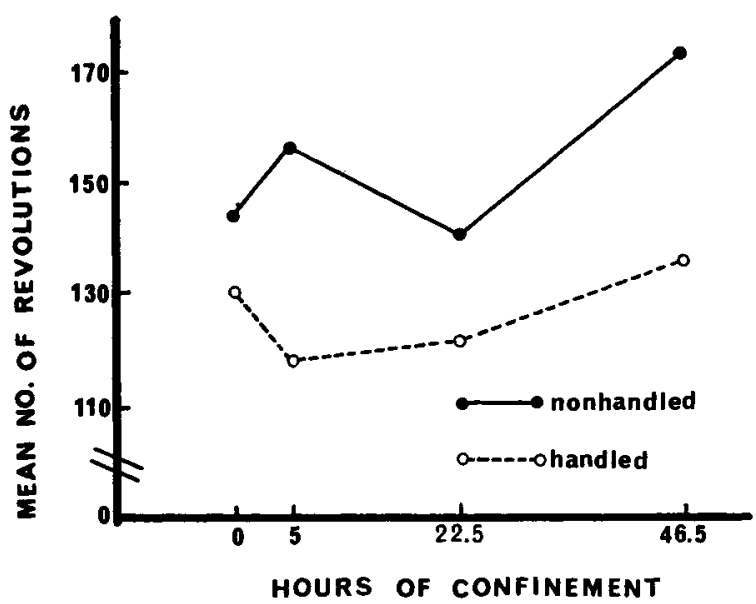

Fig. 1. Activity level as a function of hours of confinement and infantile handling.

before the testing was to begin. The tests always took place between the hours of $6: 00$ to $7: 30$ p.m. For the $46-1 / 2 \mathrm{hr}$. condition Ss were placed in the small cages as soon as they were removed from the activity wheels after the preceding test trial. The Ss in the control condition were left in the group cage with another cage. mate throughout the $46-1 / 2 \mathrm{hr}$. period prior to testing. Food and water was present in the living cages and in the testing wheels at all times.

The activity was measured by Wahmann wheels (Hill, 1956). Before the test, $S$ was placed in the small cage adfoining the wheel and was confined there for $5 \mathrm{~min}$. At the end of this period the door to the wheel was opened and the test began. This procedure was introduced in order to minimize any subsequent wheel running resulting from the generalized excitement induced by placing $S$ in the wheel. Each $S$ was left in the wheel for $1-1 / 2 \mathrm{hr}$., then removed, and a reading was taken from the counter attached to the wheel.

Throughout the course of this experiment Ss were living under a 24-hr. light cycle. The previous generation from which these $\mathrm{Ss}$ came were ralsed by the supplier under continuous illumination. For this reason it was decided that Ss should be maintained under a similar illumination schedule.

\section{Results and Diseussion}

An analysis of variance of the activity scores indicated that duration of deprivation $(F=3.77$, $d f=3 / 66$, $p<.05)$ and trial block replications $(F=18.70, \mathrm{df}=3 / 66$, $p<.01)$ were significant. However, there was no sig- nificant difference between the activity level of the handled and the control Ss $(F=1.27, d f=1 / 22, p>.05)$. A plot of the activity scores of the handled and nonhandled Ss under each of the activity deprivation conditions is shown in Fig. 1. These scores represent the average of those over successive testings for four trial blocks.

It can be seen that although the differences were not significant, the nonhandled Ss showed a level of activity which was consistently higher than that shown by the handled Ss under all levels of activity deprivation. An inspection of this figure suggests that Ss in the handled group exhibited little increase in activity as a result of their confinement conditions. However, Ss in the nonhandled (control) group did show greater activity under the $46-1 / 2 \mathrm{hr}$. activity deprivation condition than they did under the shorter confinement periods.

When the Scheffe method was used to test for differences among the deprivation conditions, the comparison between $46-1 / 2 \mathrm{hr}$. confinement and all the other deprivation periods indicated a significant difference $(\underline{S}=3.203, d f=3 / 33, p<.05)$. All other comparisons were not significant at the .05 level. These results differ in part from those found by Hill (1956). When he tested for differences between adjacent points on the curve with the t-test for matched pairs, Hill found that only the difference between 5 and $24 \mathrm{hr}$. was significant $(p<.02)$. However, the difference between 24 and $46-1 / 2 \mathrm{hr}$. approached significance.

Despite these differences, the results of this study suggest that there is no empirical basis for rejecting the concept of "activity as an autonomous drive."

\section{References}

Ader, R. Gastric erosions in the rats: Effects of immobilization at different points in the activity cycle. Science, 1964, 145, 406-407.

Hill, W. F. Activity as an autonomous drive. J. comp. physiol. Psychol., 1956, 46, 15-19.

Levine, S. Psychophysiological effects of infantile stimulation. In E. L. Bliss (Ed.), Roots of behavior. New York: Hoeber, 1962.

Marks, H. E., Narver, R. L., \& Bridges, C. C. The effect of activity deprivation upon subsequent activity. Psychon. Sci., 1966, $6,423-424$.

Shirley, M. Studies of activity: II. Activity rhythms: age and activity; activity after rest. J. comp. Psychol., 1928, 8, 159-186.

Wong, R. Infantile handling and performance in the T-maze. Psychon. Sci., 1966, 5, 203-204.

\section{Note}

1. Aided by a grant to the first author from the Dean's Committee on Research of the University of British Columbia. 